\title{
Non-Adoption of Dynamic Pricing in Traditional Taxi Dispatch Organizations
}

\author{
Erkki Tervo \\ University of Oulu, Finland \\ erkki.tervo@oulu.fi
}

\author{
Karin Väyrynen \\ University of Oulu, Finland \\ karin.vayrynen@oulu.fi
}

\begin{abstract}
Dynamic pricing (DP) was introduced into the taxi industry through ride-sharing platforms such as Uber. Prior research has identified benefits of DP for ridesharing organizations, drivers and consumers. A legal reform in Finland in July 2018 made DP of taxi rides legally possible. However, even though traditional Finnish dispatch organizations have adopted different technology (e.g., ride-hailing apps), they have not adopted DP. To find out the reasons for the non-adoption, we conducted a qualitative case study among Finnish dispatch organizations. Utilizing IT artifact as an analytical lens, we identified ten aspects related to the technology, the structure and the context within which $D P$ is embedded that help explain why it has not been adopted. We propose that DP in the taxi industry should be seen more broadly than just as "Uber-type" realtime DP, as it has been viewed in previous literature. Our findings have implications for research and practice.
\end{abstract}

\section{Introduction}

The sharing economy has been a disruptive force in the traditional taxi industry [1]. While the traditional taxi industry usually employs linear pricing models, i.e., where pricing is independent of real-time supply vs. demand [2], ride-sharing platforms often employ dynamic pricing (DP). DP means that the price of a ride dynamically changes based on (almost) real-time supply of and demand for rides [3]. Uber's surge pricing and Lyft's prime time pricing are forms of DP [4]. In surge pricing, prices for taxi rides are lower when there is "normal" demand but rise when demand is peaking [2].

The traditional taxi industry often is (quite heavily) regulated, including the pricing for taxi rides [5]. Ridesharing platforms such as Uber enter new markets rapidly, even in situations where their operations might not be legal [6]. Ride-sharing platforms have represented a legal grey area in many of the countries and cities in which they started to operate [7]. This has led to regulative responses where current taxi industry regulations are being updated [5, 8, 9]. IS research already has established that (IT) regulation affects the development, adoption and use of technology [10-12].

In Finland, Uber has been operating between 20142017, until the Appeal Court in Finland judged UberPop drivers to operate illegally [13]. A regulative reform called the "Act on Transport Services" was initiated in 2016 and became effective in 2018. This reform opened the earlier heavily regulated taxi industry to competition, removed the existing pricing regulation, and changed the taximeter regulation (which previously required taxis to use a certified taximeter for a ride's price determination) to allow new technological innovations to arise on the market and allow the use of other technology than the certified taximeter [12, 13]. One aspect emphasized in the proposals for the regulative reform, as well as by the Finnish Competition and Consumer Authority, was the hope that DP would be adopted by the Finnish taxi industry. DP was argued to increase demand for transport services and to increase the occupancy rate of taxis. In the taxi industry, DP is implemented with help of technology, or "IT artifacts", such as ride-sharing platforms that utilize algorithms [2, $3]$ and connected mobile apps. Previous research found that DP leads to a higher capacity utilization rate $[1,4]$, and provides benefits to consumers through lower prices during normal demand on the one hand and better driver supply during times of high demand [4]. Linear pricing, which is typically utilized by the traditional taxi industry, has several drawbacks $[14,15]$.

Given the benefits of DP and drawbacks of linear pricing, we had expected traditional Finnish dispatch organizations - which, similar to ride-sharing platform operators, provide dispatching services to taxis without owning those taxi cars - to adopt technology-based DP after it became legally possible in 2018 . However, even though ride-hailing apps have become the norm also amongst most traditional Finnish taxi dispatch organizations, two years after the legal change in Finland DP was still being utilized only by international ride-sharing platform operators. We therefore ask the research question: "Why is technology-based DP not adopted by traditional Finnish dispatch organizations 
after an enabling legal reform?"

To answer this question, we conducted a qualitative case study among traditional Finnish taxi dispatch organizations in spring 2020, almost two years after the regulation changed. We utilize Benbasat and Zmud's [16] conceptualization of the IT artifact as an analytical lens to make sense of our findings. We make two contributions to extant IS research: First, we identified ten factors that help explain the non-adoption of technology-based DP in the taxi industry. Second, we argue that DP in the taxi industry might be extended to also other types than just "Uber-type" real-time DP.

\section{Related research}

\subsection{Pricing regulation in the taxi industry}

Pricing in the taxi industry has often been subject to regulation. Pricing in a regulated taxi industry usually is implemented as linear pricing. Linear pricing means that the fee the consumer pays for the ride is strictly proportional to the quantity that is being purchased [17]. This "quantity" in taxi ride pricing usually are the distance/length and the duration of the trip [17, 18]. Some of the parameters that can be defined by the pricing regulation are, e.g., the (maximum) daytime and/or nighttime tariff, initial fee, fare/km, fare/minute, possible pre-order fees and fees for additional services [19]. How the prices are concretely formed can differ substantially depending on the local/national regulation. Price regulation decreases the danger of being overcharged, but linear pricing also has some drawbacks. As prices are independent of current supply and demand for rides, compared to an optimal pricing situation, prices can be seen to be "too high" during times of low demand, whereas they are "too low" during times of high demand or peak times [14]. Drivers might choose not to work during peak times because of traffic congestion at those times [15].

In Finland, the old pricing regulation required the use of linear pricing in all taxi dispatch organizations, and many continued to use it after the regulative change. Until July 2018, every taxi car in Finland had to use a certified taximeter for price determination of the ride.

\subsection{Dynamic pricing in the taxi industry}

While IS research has addressed ride-sharing platforms more generally [e.g., 20], we could not find any studies in core IS outlets (Basket of 8 journals and main IS conferences) that would have focused on DP in the context of ride-sharing. Therefore, we lean on other disciplines for a review of DP research. We found that research on DP in the taxi industry has exclusively focused on Uber-type, real-time pricing.
Ride-sharing platforms, such as Uber, are digital platforms which create two-sided markets that consist of demand (taxi ride consumers) and supply (drivers) sides by providing a mobile application and facilitating transactions between the demand and the supply side [2]. Ride-sharing platforms implement algorithm-based DP which they used to improve their completion rate (i.e., the percentage of requests of rides that are fulfilled) [21]. Algorithm-based DP works by determining the optimal pricing for the current situation on the market in real-time, and the algorithm uses real-time input data, including the current supply and demand situation and road conditions, to determine optimal pricing at a trip's origin point [3]. The algorithm also tries to predict the relation between demand and supply for the next few minutes or hours [21].

Benefits of DP. Compared to linear pricing, DP helps to provide enough supply for demand, because drivers operate in response to market profitability [17]. This is especially true when drivers are required to work under unpleasant conditions to match demand, such as rainy days, where traditional taxi drivers usually would not act differently under different weather conditions [18]. At times of high demand, ride-sharing platforms encourage drivers to operate and customers to postpone their trips by dynamically increasing prices until the market situation is balanced [21]. From the ride-sharing platform's revenue maximization perspective, DP outperforms linear pricing and provides near optimal profit compared to other pricing models [3, 4].

Drawbacks of DP. While DP can be seen beneficial for ride-sharing platforms, drivers and customers, also drawbacks have been identified. DP encourages both drivers and customers to act strategically, which in turn harms ride-sharing platforms' long-term success [22]. From the customer's perspective, problems arise when DP leads to heavy price increases at the worst time [22, 23]. As the DP algorithms have not been made public by ride-sharing platforms, it is impossible for third parties to predict future prices and demand patterns, and to be sure that ride-sharing platforms are not manipulating prices [21, 24]. The opaque algorithm also causes customers to be confused and annoyed with nontransparent pricing methods and might even prevent them from making quick decisions to request a ride [22, $23,25]$. To prevent such situations, some countries/ cities have implemented regulations to limit price increases caused by DP, and even set a limit on how much ride-sharing platforms can charge the customer [22].

In summary, even though some drawbacks of DP have been identified mainly from the customers' point of view, benefits have been identified from the perspective of a profit-maximizing ride-sharing platform. This would support the assumption that also traditional taxi dispatch organizations would want to implement DP. 


\section{Methodology}

Our research is conducted as a qualitative, interpretive case study [26], not with the goal to generalize but to understand and make sense of the phenomenon we investigate [27]. Case study research is suitable for research work that aims to answer "how" and "why" questions [26]. As we investigate why traditional Finnish dispatch organizations have not adopted DP after the regulative reform called "Act on Transport Services" came into effect in 2018, case study is a suitable research approach.

\subsection{Data collection}

We collected data in two steps, with the intention to eventually make a well justified and informed choice regarding the interviewee selection.

First, to understand more generally how pricing has changed, we identified what pricing models traditional Finnish dispatch organizations overall employed two years after the deregulation of pricing models and technology. We collected publicly available information on pricing models of 34 traditional Finnish dispatch organizations from these dispatch organizations' websites, social media and other sources found using Google search. We then identified three pricing model types (see Section 4.1) by identifying parameters utilized for ride pricing by these dispatch organization and analyzing in what different ways they were combined.

Second, we conducted 8 in-depth interviews with 9 interviewees (one interview was a group interview with 2 interviewees) with an average length of 76.76 minutes. We selected those dispatch organizations so that we had representatives from all three different pricing models. Of the eight dispatch organizations we interviewed, one organization used the distance-based pricing model type, six used the distance- and duration-based pricing model type, and one used the duration-based pricing model type (see Section 4.1 for information on these pricing model types). The selected dispatch organizations differed in important key characteristics (geographic operation area; number of taxis dispatched between about 50 to more than 1000) to get a diverse insight into why DP has not been adopted. The dispatch organizations used different combinations of key technologies that affect DP possibilities (dispatch system, taximeter, ride-hailing app), with different technology vendor combinations for these technologies. All interviewed organizations offer their customers the possibility to hail a ride via an app. For data anonymization reasons, we cannot reveal which dispatch organization (DO) represented which pricing model. Table 1 summarizes information about the interviewed organizations as well as background information regarding the key technology.

In the interviews, we asked about the interviewees' background and that of the dispatch organization they represented, the organization's old and current pricing model, about the technology that is involved in price determination (ride-hailing app, certified taximeter, and dispatch system), what they think about DP in general, and why they do not (yet) implement DP.

\subsection{Interview data analysis and "IT artifact" as analytical lens}

We transcribed all interviews non-verbatim and used thematic analysis to identify, analyze, organize, describe, and report themes [28]. In the first step of the interview data analysis, we extracted from each interview transcript information about why traditional Finnish dispatch organizations have not (yet) implemented Uber-type technology-based DP in the two years after the legal change in July 2018. In the second step, we ordered the information from the eight interviews into themes. We identified ten aspects or constraints $(\mathrm{C} 1-\mathrm{C} 10)$ that help explain why technology-based DP has not been adopted. These constraints were not only technology-related, but due to other aspects as well. In the third step of the data analysis, we utilized Benbasat and Zmud's [16] 4-layer conceptualization of the IT artifact as "the application of IT to enable or support some tasks(s) embedded within a structure(s) that itself is embedded within a context(s)." (p. 186). Their conceptualization of the IT artifact includes also organizational/social aspects in addition to technical aspects [29]. While we are aware of critique towards this IT artifact conceptualization as being too all-encompassing [e.g., 30], we nevertheless found it very useful, as this conceptualization acknowledges that technology enables or supports some $\operatorname{task}(s)$ - this is central to our study. Benbasat and Zmud [16] provide an example of budget planning as IT supported task: the "task structure" is related to the formal enterprise budget planning process, institutional budgeting policies, rules and practices, and corporate/ divisional objectives; the "task context" entailed, e.g., enterprise and divisional values and norms, industry and firm business conditions, and personal agenda. In our study we equate DP to the "budget planning" example. We conceptualize DP as an IT supported task that is not being adopted within a certain structure (e.g., the traditional Finnish dispatch organization in contrast to a ride-sharing platform organization; institutional pricing policies, rules and practices; and corporate objectives of the dispatch organization) that is embedded within a certain context (e.g., values and norms of the dispatch organization, taxi industry and business conditions). 
Table 1. List of interviewees, represented dispatch organizations, their technology providers and their main operational area in Finland (anonymized).

\begin{tabular}{|c|c|c|c|c|c|c|}
\hline $\begin{array}{c}\text { Dispatch } \\
\text { organization }\end{array}$ & $\begin{array}{c}\text { Interviewee number, } \\
\text { Title }\end{array}$ & $\begin{array}{c}\text { Dispatch system } \\
\text { vendor }\end{array}$ & $\begin{array}{c}\text { Taximeter } \\
\text { vendor }\end{array}$ & $\begin{array}{c}\text { Taximeter } \\
\text { type }\end{array}$ & $\begin{array}{c}\text { Ride-hailing } \\
\text { app vendor }\end{array}$ & $\begin{array}{c}\text { Main operation } \\
\text { area in Finland }\end{array}$ \\
\hline DO 1 & $\begin{array}{c}\text { 1a, CEO; 1b, Customer } \\
\text { relationship manager }\end{array}$ & V 1 & V 2 & Traditional & V 1 & Northern \\
\hline DO 2 & 2, CEO & V 2 & V 2 & Traditional & V 2 & South-Western \\
\hline DO 3 & 3, CEO & V 2 & V 2 & Traditional & V 2 & Southern \\
\hline DO 4 & 4, CEO & V 1 & V 3 & Traditional & V 1 & Western, Central \\
\hline DO 5 & 5, CEO & V 4 & V 2; V 4 & Traditional & V 5 & Southern \\
\hline DO 6 & 6, CFO & V 6 & V 2 & Traditional & in-house & Nationwide \\
\hline DO 7 & 7, CEO & V 6 & V2; V 7 & Traditional & in-house & Southern \\
\hline DO 8 & 8, CEO & V 8 & V8 & Softmeter & V 9 & Southern \\
\hline
\end{tabular}

\section{Findings}

We first summarize, based on our review of 34 dispatch organizations' pricing models, the three types of pricing models that have been utilized two years after the deregulation of the Finnish taxi industry. Then, we describe the technology that is at the core of pricing taxi rides in the Finnish taxi industry. Last, we summarize the constraints to technology-based DP adoption arising from the technology that should enable the DP task, from the task structure, and from the task context.

\subsection{Pricing model parameters and model types}

Before the regulative reform called "Act on Transport Services" came into effect on 1.7.2018, taxi ride pricing in Finland was heavily regulated, and DP was not possible due to that regulation. With the regulative reform, pricing was deregulated and the taximeter regulation was changed, so that the price of a ride could also be determined with other technology than a certified taximeter (which was the only allowed technology before the legal change). The pricing model before the legal change consisted of three main parameters: (1) a basic fee that had to be paid independently of trip distance or waiting fee and was dependent on time-of-day and weekday, (2) a trip distance fee $($ fare $/ \mathrm{km})$ which was dependent on the distance driven and on the number of persons riding in the car, and (3) a waiting fee (fare/hour) which specified the fee applied when the car was standing or if it drove at a very slow pace. Maximum fees for each parameter were set by the Finnish government. This pricing parameter structure is also built into certified taximeters.

After the regulative reform, four main parameters are utilized in ride pricing: a basic fee that is independent of distance and duration of the trip, a trip distance fee (fare $/ \mathrm{km})$, and either a trip duration fee (fare/min or fare/hour) or a waiting fee (fare/min or fare/hour). In addition, different dispatch organizations also make use of three sub-parameters that affect the fare: the number of persons who ride in the taxi, the time-of-day (or weekday) of the ride, or the fare may be independent of the amount of persons and time-of-day. Different dispatch organizations have different ways to utilize different sub-parameters in connection to the four main parameters to fine-tune their fares. Especially the time-of-day sub-parameter has been fine-tuned by dispatch organizations in response to having observed differences in demand/supply for taxi rides, e.g., at certain times during certain days. Whereas the basic fee before the regulative change was independent of timeof-day or weekday, many dispatch organizations now set the basic fee to be dependent on the time-of-day and/or the number of persons.

Based on these parameters, we identified three distinct pricing models. In the "distance-based pricing model", the taxi ride price is based on a basic fee, a trip length fee and a waiting fee. This pricing model is practically the same as the pricing model that was used before the regulative change and does not apply a trip duration fee. 24 of the 34 dispatch organizations whose pricing model we analyzed utilized this model. In the "distance- and duration-based pricing model", a trip distance fee and a trip duration fee (which replaced the waiting fee in pricing model before the regulative change) are combined. In the "duration-based pricing model", the taxi trip's price consists of a fixed basic fee and the trip duration (which is the only variable part of the price). In all three pricing models, the identified subparameters are utilized in different combinations together with the main parameters.

Some dispatch centers have implemented a minimum fare for each taxi ride to make sure the customer pays at least this minimum price for the ride. The main reason for this is to ensure that drivers accept 
also very short trips (where earnings would be very low without the minimum fare) instead of rejecting the ride in hope for a "better" customer (e.g., DO 6 and DO 7). Other dispatch organizations argued that the use of a higher basic fee instead of a minimum fare is another option to ensure a certain minimum earning for the drivers while at the same time being more transparent for the customer (e.g., DO 5 and DO 8). In addition to above pricing models, some traditional Finnish dispatch organizations have also implemented fixed pricing, which can be offered by a driver directly to the customer in a street-hailing or rank situation, offered to the customer upon request when the customer orders a taxi by phone, or can be part of advertisement or special campaigns (e.g., during large events). Most commonly, fixed-priced rides are being implemented in ride-hailing apps. In fixed-priced rides, the price is calculated with help of different parameters and given to the customer before the trip begins. Usually, the price is calculated based on estimations for the trip length and distance (based on information about starting point and destination of the taxi ride) - utilizing some map service like Google maps - and calculating the price then based on the dispatch organization's valid pricing parameter scheme. Fixed-priced rides would theoretically allow for an implementation of Uber-type real-time DP. However, amongst the organizations we studied, none implemented DP where the price is adapted based on real-time supply of and demand for rides - even though some offered fixed-priced rides in their apps.

\subsection{Information technology in ride pricing}

Mainly three types of technology, separately or together, are utilized for determining the price of a ride and informing the customer about that price. Certified taximeters, even though not any more required by the law, were used by seven of the eight dispatch organizations that we have interviewed. Certified taximeters are nowadays a combination of a "physical device" that is fixed-installed in the car and software. They calculate the price of the ride in real-time based on the driven distance and/or time passed and additional pricing parameters and display the price of the ride in real-time. Softmeters, which usually are apps that run on some mobile device, are not fixed-installed in the taxi and measure the distance with help of GPS. They are usually flexible in their setting/updating of pricing parameters. Dispatch systems, which are utilized by taxi dispatch organizations, are information systems that usually automatically dispatch taxis to pick up customers based on an algorithm. They utilize map information (e.g., Google Maps) for time and distance estimation and can provide information to certified taximeters, softmeters, and/or ride-hailing apps. Ride- hailing apps allow the customer to order a taxi. Some apps utilized by traditional Finnish dispatch organizations only give a price estimate - the actual price of the ride is calculated during the ride with a certified taximeter. Other apps give a fixed price to the customer, and this fixed price is based on information provided by the dispatch system. The ride-hailing app is usually integrated with the dispatch system, and in some cases also with the certified taximeter.

\subsection{Task: Technology-based ride pricing}

Technological constraints stemming from the dispatch system technology, certified taximeter technology, and ride-hailing app technology - as well as the combination of all of these - heavily affect what type of pricing model is even technically possible, and help explain the non-adoption of technology-based DP.

C1 - Constraints from dispatch system technology. Several interviewees mentioned challenges regarding their current dispatch system capabilities to process real-time input data for real-time DP needs. The dispatch system from Vendor 1, which was used by several of the organizations interviewed, was mentioned to be capable of processing only "a few" variables, is not very flexible, and the system provider is not very quickly implementing new desired features. The system, e.g., does not support fixed pricing. One reason for this is that Vendor 1's system has been built to match the requirements of the earlier highly regulated taxi markets resulting in inflexibility and closed interfaces. On the other hand, Vendor 2's and Vendor 6's dispatch systems were seen to technologically allow for the implementation of DP. Vendor 6's system was seen as flexible, having open interfaces which allow a dispatch organization to develop its other technology more freely around the dispatch system.

C2 - Constraints from certified taximeter. One constraint to the implementation of DP is the traditional, certified taximeter. Most certified taximeters require that pricing parameters are set in advance. Updating the list of prices/parameters into the taximeter in the car may take up to a week - depending on the taximeter vendor and the type of taximeter. Therefore, prices usually cannot be updated quickly enough to respond to real-time demand and supply situations. In addition, the inability to set pricing models freely was mentioned as a factor by interviewees - some certified taximeters put restrictions on how prices can be formed. Softmeters would be flexible enough for DP to be implemented. However, due to regulative unclarity (see Section 4.4), even one of the dispatch organizations that already has developed their own softmeter did not yet start to use it for pricing. DO 8 is the only dispatch organization of those we interviewed that has a softmeter in use. 
C3 - Constraints from ride-hailing apps. The technological implementation of ride-hailing apps and a lack of technological development of some ride-hailing apps by the vendor affects the possibility to implement DP. One dispatch organization which had acquired their ride-hailing app from their dispatch system vendor mentioned that fixed pricing is not possible in their ridehailing app. Also, some dispatch organizations in different geographical areas use the same basic app which limits the possibilities regarding custom features specific to a certain area. E.g., DO 2 could not implement zone-boundary pricing in their ride-hailing app, because the same app is, according to Interviewee 2, "also used in other areas" by other dispatch organizations which do not have that pricing method in use. Similarly, an app developed for different taxi markets' needs affects the pricing possibilities. For example, one dispatch organization's ride-hailing app had already been developed for a different market where a certain pricing model has been used. Thus, the dispatch organization implemented that same pricing model also in Finland. In summary, the amount and complexity of required technological integrations restricts the possibilities to implement DP.

\subsection{Constraints arising from the task structure}

The task structure is related to formal organizational processes and objectives, and institutional policies, rules and practices. We identified three aspects related to the task structure of ride pricing.

C4 - The management board or the owners of the dispatch organization are not behind the idea of DP. Most traditional taxi dispatch organizations in Finland have under the old taxi industry regulation been established as cooperative which is owned by taxi entrepreneurs. These cooperatives were not formed to make profit, but instead to offer taxi dispatching services to the owners of the cooperative. Most interviewees mentioned that their dispatch organization is not going to implement DP. The main reason for that is that either management or owners are not behind the idea. Interviewee 7 said about implementation of DP as fixed-priced ride that "we could implement it but our owners, taxi entrepreneurs, are not ready to completely move to that", and mentioned that they are going to implement DP in some time frame later. Reasons include an unwillingness to implement DP, a lack of interest, and that it is not worth to implement DP due to the low number of client trips. Only Interviewee 6 mentioned that their dispatch organization is going to implement DP "as soon as the technology allows it".

C5 - Pricing regulation sets additional restrictions. Even though the deregulation of Finnish taxi markets made it possible for dispatch organizations to freely set their pricing, the pricing regulation also sets the requirement to clearly display the pricing parameters and fares in the window of the taxi. This requirement, basically, prevents dynamic update of pricing in rides that are taken from a taxi stand or by street hailing.

C6 - Uncertainty towards softmeter regulations. While certified taximeters have been seen to be a main constraint to prevent DP, softmeters have been considered a valid answer to this problem. According to Interviewee 5, softmeters would lower their costs as certified taximeters are expensive to renew in big fleet of vehicles. Interviewee 7 mentioned that the use of softmeters would solve their problems regarding quick pricing adjustments to taximeters. However, at the time of our data collection, there was some unclarity in the Finnish taximeter regulation regarding whether these softmeters are allowed, and more importantly, whether they would be allowed as full replacement to certified taximeters after the ongoing (autumn 2020 - spring 2021) new reform of the laws that regulate the taxi industry. This uncertainty has stalled dispatch organizations in taking into use certain technological innovations that would technically already make DP possible. Of the dispatch organizations we interviewed, only one uses a softmeter, but the organizations' drivers still need to use also a certified taximeter to comply with the requirements for public sector trips (see Section 4.5).

\subsection{Constraints arising from the task context}

The task context is related to, e.g., enterprise values and norms, industry and firm business conditions, personal agenda and relationships. We identified four aspects related to the task context of ride pricing.

C7 - Other stakeholders' requirements that demand the use of a certain technology. In Finland, the Social Insurance Institution (SII) subsidizes taxi rides for certain customers. These subsidized rides can make up a major share of the overall taxi ride orders that a certain dispatch organization receives. However, in these subsidized taxi rides, the SII requires taxi drivers to use a certified taximeter. Therefore, even though the taximeter law would allow for other technology to be used than a certified taximeter, and thus would make DP easier, the business conditions coming from another stakeholder practically prevents it (or would allow the use of a different technology only in addition to the certified taximeter and thus increase overall technology costs).

C8 - Upholding traditional taxi industry values. Several interviewees mentioned that they do not see DP as suitable for the traditional taxi industry. Interviewee 3 mentioned that as long as they are a "traditional dispatch organization", they cannot implement DP. According to Interviewee 3, the traditional Finnish dis- 
patch organization differs from ride-sharing platforms by that taxi can be ordered by calling a dispatch organization and that "the price does not vary based on how many cars we have and how many customers are in line". Interviewee 5 said that DP is based on "occasionnally occurring variables that cannot be predicted", such as the weather's effect. The importance of transparent pricing was emphasized by several interviewees, and DP is considered opaque, because pricing terms are invisible for both customers and drivers.

C9 - DP seen as problematic from the customer's perspective. Interviewee 2 mentioned that "if the price would fluctuate quite a lot at different times, then it would quite suddenly put the customer in a situation where they would have to consciously follow all the time what the price of a taxi (ride) is at any given time". This was considered problematic or unwanted. According to Interviewees 2 and 8, this creates the risk that customers might stop using taxi services. Interviewee 4 summarized Finnish taxi customers as being "oldfashioned" in the sense that they do not like surprises. The dispatch organization that utilized the "durationbased model" mentioned that they did not change their pricing model when the legislation reform took effect, but instead simplified their pricing model to make the price estimation easier for customers. Another dispatch organization changed its pricing model to match the new pricing model employed by other, competing, dispatch organizations, because they thought it would be easier for customers to compare pricing between different taxi service providers. One challenge regarding fixed-priced rides is to make sure that the customers understand the terms of contract, e.g., what the trip price includes and what it does not.

C10 - DP seen as problematic from the driver's perspective. Several interviewees pointed out that it is important that also drivers understand - and support the pricing model employed by the dispatch organization, as Interviewee 4 states: "after all, our salesmen on the field are drivers". One specific issue mentioned by interviewees are drivers' understanding of fixed-priced rides' terms of contract, or what to do if a customer wants to change a trip's parameters by, e.g., changing the ride destination during the ride. In this case, the distance or time estimation would be different from the original estimation, and therefore the price could not anymore be the fixed price first given to the customer. Interviewee 7 mentioned that they already would have the technical capability to implement DP as fixed-priced rides, but do not implement it for some of the reasons reported above.

\section{Discussion}

With this paper, we set out to answer the question why traditional Finnish dispatch organizations have not adopted DP after a regulative reform that would have made DP possible. We contribute to extant research in two ways. As our main contribution to IS research, we identified the factors that help explain the non-adoption of technology-based DP in the taxi industry. We discuss our findings in the light of prior research on the (non-)adoption of technology. Second, we contribute to research on DP in the taxi industry by extending understanding of DP from only Uber-type real-time DP to other DP forms. We show that Finnish pricing models have become more dynamic, and some models seem to tackle similar "challenges" as Uber-type DP has been argued to tackle. We argue that our understanding of DP in the taxi industry might be extended to also other types than just Uber-type DP.

\subsection{Summary of findings - a model of non- adoption of technology for dynamic pricing}

Several benefits such as a higher capacity utilization rate, lower prices during normal demand and increased driver supply during times of high demand have been identified as benefits of Uber-type DP [1, 4]. Our findings reveal that even though regulation has an impact on the development, adoption and use of technology [10-12], it is not enough to establish a regulatory framework that would allow for the use of new technology and DP, as there are several other constraints to adopting technology-based DP. Figure 1 summarizes our findings regarding constraints to the adoption of technology-based DP, organized along Benbasat and Zmud's [16] 4-layered conceptualization of the IT artifact. We will discuss some of these constraints in the light of prior IS research on the (non-)adoption of technology next.

Constraints related to technology. The most significant constraint to the implementation of DP - if a dispatch organization would want to implement it seemed to be related to the technology already used by the dispatch organizations. DP requires the ability to process real-time input data from multiple sources and the ability to adjust pricing dynamically in real-time to match the current supply- and demand situation [3]. Currently, most dispatch systems used by traditional Finnish dispatch organizations do not have such capability, and further development of these systems seems to have challenges: closed interfaces of systems that prevent own development around systems, legacy baggage of systems that have been built for a regulated taxi market, and complexity of the whole technological stack - especially if the dispatch system, the certified taximeter, and possibly a ride-hailing app are provided by different vendors. Thus, in most cases, the existing technology cannot be utilized for DP - it would require 


\section{Figure 1. DP adoption constraints}

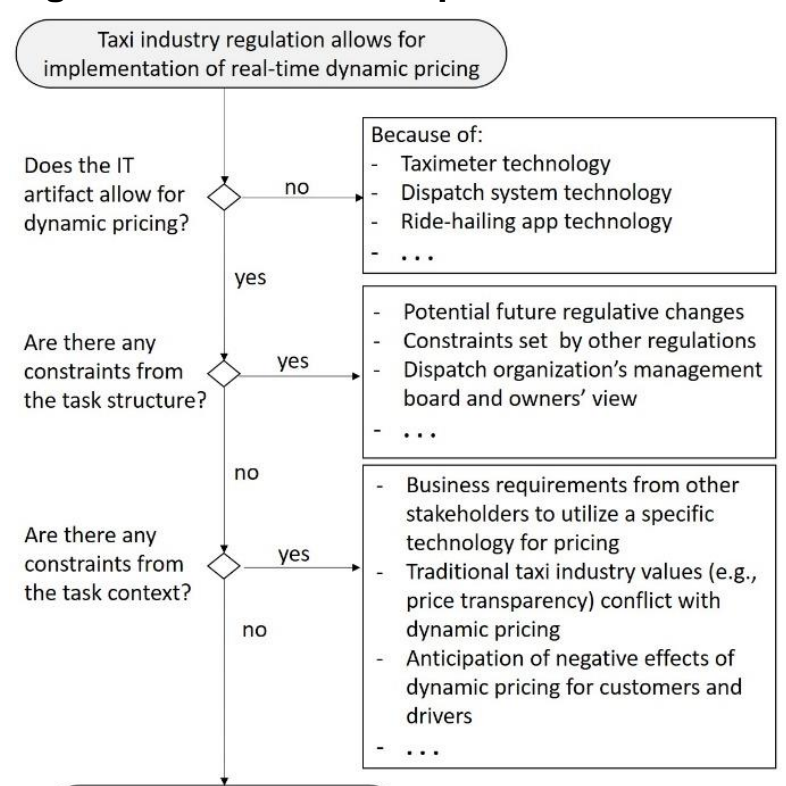

Technology-based real-time

dynamic ride pricing

replacement with or the additional investment in softmeters. Prior research has found that technologyspecific factors (e.g., complexity) of an innovation do not have an effect on technology non-adoption in cloud computing context [e.g., 31, 32] but in big data solution adoption context, complexity does have an effect on non-adoption [33]. These studies investigated adoption of new technology - in our case, only one dispatch organization had developed a separate softmeter (i.e., new technology) that could have been utilized in principle. However, regulative unclarity (C5) negatively affected the organization's willingness to switch to this softmeter, not issues related to its complexity.

Constraints from task structure. Top-management support [33, 34] and owner characteristics [35] have been identified to be important organizational factors for technology adoption, which corroborates our finding C4. Prior research also found that (strict) requirements set by regulation can lead to non-adoption of technology (e.g., adoption process of machine learning systems in clinics [36]). Also we found that regulation can stall technology adoption (C5). More importantly, we found that uncertainty arising from potential future regulative changes can be a constraint to technology adoption (C6).

Constraints from task context. Prior research identified that business partner pressure may drive organizations to adopt new technology, e.g., cloud computing [34]. Our findings, in contrast, identified business partner pressure to act as a force that supports the non-adoption of technology. In our case, the requirements set by the SII to use a certified taximeter for subsidized taxi rides (see C7) made a complete switch to softmeters difficult (or even impossible, as the dispatch organization and its drivers may lose a substantial part of their customers through that). Prior research has emphasized that incompatibility of an innovation with existing values, past experiences and needs of potential adopters can help explain nonadoption of technology [34]. Our findings corroborate this, as we found that traditional taxi industry values such as price transparency $(\mathrm{C} 8)$ and considerations of what customers and drivers value (C9-C10) are constraints to adoption of DP. As DP is not transparent $[23,25]$, it clashes with the ideal of price transparency.

Interestingly, previous research has identified competitive or external pressure to affect technology (non-)adoption [e.g., 34, 37]. In our case this aspect surprisingly did not come up. This might indicate that no external pressure from, e.g., customers or competitors existed to adopt technology-based DP. Our finding that dispatch organizations assume customers to be in favor of linear pricing (C9) supports this interpretation.

\section{2. "More dynamic" pricing}

Previous research on DP in the taxi industry has focused solely on Uber-type, real-time, DP. While none of the dispatch organizations we have interviewed has implemented real-time DP, pricing of taxi rides in Finland has nevertheless become much more dynamic than it was before the regulative change. As indicated in the context of DP in electricity markets, DP can also include, for example, time-of-use rates where energy costs a different price in blocks over a day [38]. Timeof-day pricing [see also 14] and weekday-based pricing in the Finnish taxi industry is equivalent. While time-ofday or weekday previously has only affected the basic fee, now it is used also in the trip distance and trip duration fees. This means that the price for the same taxi ride from place $A$ to place $B$ can have a quite different price during different times in the day, or on different weekdays. Similarly, the utilization of the trip duration fee, which has replaced the waiting fee in the distanceand duration-based model, practically means that the price of the taxi ride now responds more dynamically to changes in the traffic situation. This also makes it more difficult for the customer to estimate the actual price of the ride when they cannot predict the traffic situation.

Two benefits of DP identified by previous research are that it helps to increase supply during times of high demand, but also that price increases during times of high demand induce some taxi riders to postpone their ride $[17,21]$. In addition, surge pricing leads to lower prices during times when demand is "normal" or low [2]. We found that several aspects of pricing models after the legal change aim at similar effects. By using 
the time-of-day sub-parameter, the price level of rides is adjusted to times of high vs. low demand. By setting a minimum price for rides, dispatch organizations might aim to ensure that drivers also accept short rides during times-of-day when the pricing level (and thus income for the driver) is lower. Previous research argued that linear pricing can lead to a situation where drivers decide not to work during traffic congestion times [e.g., 15]. The utilization of the trip duration fee parameter in distance- and duration-based pricing models and in the duration-based pricing model could be argued to address this shortcoming of linear pricing. Thus, we argue that there are also other forms of DP than Uber-type realtime pricing possible in the taxi industry worth being investigated in more detail by future research.

\section{Conclusion}

With this paper, we set out to answer why traditional Finnish dispatch organizations have not adopted Ubertype DP after a legal reform that had made DP possible. We conducted a qualitative case study amongst traditional Finnish dispatch organizations to answer this question. We looked at the technology-based task of DP through the lens of Benbasat and Zmud's [16] IT artifact conceptualization. Through our investigation of pricing models utilized by traditional Finnish dispatch organizations and our interview study, we found that several constraints exist related to technology, task structure and task context that help explain the nonadoption of technology-based DP. These constraints are strongly related to how traditional Finnish dispatch organizations have operated in the past. Bringing a concept or a practice (e.g., DP of taxi rides) that might be common in one country/organization into another country/organization where the frame-of-reference or the practice is vastly different is not easy.

Our findings have also practical implications. For regulators who seek to advance DP in the taxi industry, but possibly also in other transport-related contexts, our findings give valuable information on aspects that might act as counterforces to the regulator's assumptions or intentions. Our results can be utilized by regulators in countries that have a similar taxi industry and are going through a deregulation process with specific objectives in mind they want to accomplish.

Our research has also limitations, which open directions for future research, too. Only eight dispatch organizations were interviewed and involving more organizations might have led to additional insights. However, by investigating first different pricing model types and then selecting representatives of all different pricing models, and by ensuring that these organizations were from different geographic areas of different size, and had different combinations of the core IT systems, we attempted to ensure sufficiently diverse insights to gain a deep insight into the phenomenon under investigation. Future IS research could conduct a similar study on the (non-)adoption of Uber-type DP in the traditional taxi industry in a different country to corroborate or extend our findings. In addition, our findings indicate the importance of laws and regulation, and regulative unclarity or uncertainty on technology adoption. This could also be an interesting direction for future IS research on technology (non-)adoption.

\section{Acknowledgements}

The second author is grateful for research funding received from the Jenny and Antti Wihuri Foundation.

\section{References}

[1] J. Cramer and A. B. Krueger, "Disruptive Change in the Taxi Business: The Case of Uber," American Economic Review, vol. 106, no. 5, pp. 177-182, 2016.

[2] S. Guo, Y. Liu, K. Xu, and D. M. Chiu, "Understanding ride-on-demand service: Demand and dynamic pricing," in 2017 IEEE International Conference on Pervasive Computing and Communications Workshops (PerCom Workshops), pp. 509-514, 2017.

[3] M. Asghari, and C. Shahabi, "ADAPT-Pricing: A Dynamic and Predictive Technique for Pricing to Maximize Revenue in Ridesharing Platforms," in Proceedings of the 26th ACM SIGSPATIAL International Conference on Advances in Geographic Information Systems, (New York, USA), pp. 189-198, ACM, 2018.

[4] G. P. Cachon, K. M. Daniels, and R. Lobel, "The Role of Surge Pricing on a Service Platform with Self-Scheduling Capacity," Manufacturing and Service Operations Management, vol. 19, no. 3, pp. 368-384, 2017.

[5] T. Cetin, and E. Deakin, "Regulation of taxis and the rise of ridesharing," Transport Policy, vol. 76, pp. 149-158, 2019.

[6] A. Witt, N. Suzor, and P. Wikström, "Regulating ridesharing in the peer economy," Communication Research and Practice, vol. 1, no. 2, pp. 174-190, 2015.

[7] Y. Crespo, 'Uber v. Regulation: 'Ride-Sharing' Creates a Legal Gray Area." University of Miami Business Law Review, vol. 25, no. 1, pp. 79-110, 2016.

[8] D. E. Rauch, and D. Schleicher, "Like Uber, but for local government law: the future of local regulation of the sharing economy," Ohio State Law Journal, vol. 76, no. 4, pp. 901-963, 2015.

[9] A. Tzur, "Uber Über regulation? Regulatory change following the emergence of new technologies in the taxi market," Regulation \& Governance, vol. 13, no. 3, pp. 340-361, 2019.

[10] R. Bernardi, P. Constantinides, and J. Nandhakumar, "Challenging Dominant Frames in Policies for IS Innovation in Healthcare through Rhetorical Strategies," Journal of the Association for Information Systems, vol. 18, no. 2, pp. 81-112, 2017.

[11] E. Klecun-Dabrowska, and T. Cornford, "Telehealth acquires meanings: information and communication 
technologies within health policy," Information Systems Journal, vol. 10, no. 1, pp. 41-63, 2000.

[12] K. Väyrynen, and A. Lanamäki, "Policy Ambiguity and Regulative Legitimacy of Technology: Legal indeterminacy as Result of an Ambiguous Taximeter Regulation," in International Conference on Information Systems (ICIS): ICIS 2020 Proceedings, 2020.

[13] M. Koillinen, "Uber and taxi services in Finland," in Uber \& Taxis, Comparative Law Studies (R. Noguellou and D. Renders, eds.), pp. 203-215, Bruxelles: Bruylant, 2018.

[14] X. Qian, and S. V. Ukkusuri, "Time-of-Day Pricing in Taxi Markets," IEEE Transactions on Intelligent Transportation Systems, vol. 18, no. 6, pp. 1610-1622, 2017.

[15] J. Gan, B. An, H. Wang, X. Sun, and Z. Shi, "Optimal Pricing for Improving Efficiency of Taxi Systems," in Proceedings of the Twenty-Third International Joint Conference on Artificial Intelligence, IJCAI '13, pp. 2811-2818, AAAI Press, 2013.

[16] I. Benbasat, and W. Zmud, "The Identity Crisis Within the IS Discipline: Defining and Communicating the Discipline's Core Properties," MIS Quarterly, vol. 27, no. 2, pp. 183-194, 2003.

[17] H. Yang, C. S. Fung, K. I. Wong, and S. C. Wong, "Nonlinear pricing of taxi services," Transportation Research Part A: Policy and Practice, vol. 44, no. 5, pp. 337-348, 2010.

[18] A. Brodeur, and K. Nield, "An empirical analysis of taxi, Lyft and Uber rides: Evidence from weather shocks in NYC," Journal of Economic Behavior and Organization, vol. 152, pp. 1-16, 2018.

[19] R. Noguellou, and D. Renders, "Introduction," in Uber \& Taxis, Comparative Law Studies (R. Noguellou and D. Renders, eds.), pp. 7-17, Bruxelles: Bruylant, 2018.

[20] L. Kang, Q. Jiang, C.-H. Peng, C. L. Sia, and T.-P. Liang, "Managing Change with the Support of Smart Technology: A Field Investigation of Ride-Hailing Services," Journal of the Association of Information Systems, vol. 21, no. 6, pp. 1594-1620, 2020.

[21] M. Battifarano, and Z. S. Qian, "Predicting real-time surge pricing of ride-sourcing companies," Transportation Research Part C: Emerging Technologies, vol. 107, pp. 444-462, 2019.

[22] H. Yang, C. Shao, H. Wang, and J. Ye, "Integrated reward scheme and surge pricing in a ridesourcing market," Transportation Research Part B: Methodological, vol. 134, pp. 126-142, 2020.

[23] A. Basu, "Viability assessment of emerging smart urban para-transit solutions: Case of cab aggregators in Kolkata city, India," Journal of Urban Management, vol. 8, no. 3, pp. 364-376, 2019.

[24] L. Chen, A. Mislove, and C. Wilson, "Peeking Beneath the Hood of Uber," in Proceedings of the 2015 Internet Measurement Conference, IMC '15, (New York, NY, USA), pp. 495-508, ACM, 2015.

[25] S. Guo, C. Chen, J. Wang, Y. Liu, K. Xu, and D. M. Chiu, "Fine-grained Dynamic Price Prediction in Ride-ondemand Services: Models and Evaluations," Mobile Networks and Applications, vol. 25, no. 2, pp. 505-520, 2020.
[26] G. Walsham, "Interpretive case studies in IS research: nature and method," European Journal of Information Systems, vol. 4, no. 2, pp. 74-81, 1995.

[27] H. K. Klein and M. D. Myers, "A Set of Principles for Conducting and Evaluating Interpretive Field Studies in Information Systems," MIS Quarterly, vol. 23, no. 1, pp. 67-93, 1999.

[28] L. S. Nowell, J. M. Norris, D. E. White, and N. J. Moules, "Thematic Analysis: Striving to Meet the Trustworthiness Criteria," International Journal of Qualitative Methods, vol. 16, no. 1, pp. 1-13, 2017.

[29] J. Iivari, "Information system artefact or information system application: that is the question," Information Systems Journal, vol. 27, no. 6, pp. 753-774, 2017.

[30] S. Alter, "Sidestepping the IT Artifact, Scrapping the IS Silo, and Laying Claim to "Systems in Organizations"," Communications of the Association for Information Systems, vol. 12, pp. 494-526, 2003.

[31] R. El-Gazzar, E. Hustad, and D. H. Olsen, "An Institutional Lens on Cloud Computing Adoption - A Study of Insititutional Factors and Adoption Strategies," in Proceedings of the 25th European Conference on Information Systems (ECIS), (Guimarães, Portugal), pp. 2477-2492, 2017.

[32] T. Lynn, X. Liang, A. Gourinovitch, J. P. Morrison, G. Fox, and P. Rosati, "Understanding the Determinants of Cloud Computing Adoption for High Performance Computing," in 51 st Hawaii International Conference on System Sciences (HICSS-51), pp. 3894-3903, 2018.

[33] K. A. Salleh, and L. Janczewski, "Adoption of Big Data Solutions: A study on its security determinants using SecTOE Framework," in CONF-IRM 2016 Proceedings, 2016.

[34] I. M. Al-Jabri, "The Perceptions of Adopters and NonAdopters of Cloud Computing: Application of Technology-Organization-Environment Framework," in ICEB 2014 Proceedings, (Taipei, Taiwan), 2014.

[35] L. Sparling, M. Toleman, and A. Cater-Steel, "SME Adoption of e-Commerce in the Central Okanagan Region of Canada," in ACIS 2007 Proceedings, 2007.

[36] L. Pumplun, M. Fecho, N Islam, and P. Buxmann, "Machine Learning Systems in Clinics-How Mature Is the Adoption Process in Medical Diagnostics?," in Proceedings of the 54th Hawaii International Conference on System Sciences, pp. 6317-6326, 2021.

[37] E. Grandon, and J. M. Pearson, "E-Commerce Adoption: Perceptions of Managers/Owners of Small and Medium Sized Firms in Chile," Communications of the Association for Information Systems, vol. 13, no. 1, pp. 81-102, 2004.

[38] L. Kiesling, "Retail Electricity Deregulation: Prospects and Challenges for Dynamic Pricing and Enabling Technologies," Draft prepared for the Searle Center Annual Review of Regulation. https://www.academia.edu/32966002/Retail_electricity_ deregulation_prospects_and_challenges_for_dynamic_p ricing_and_enabling_technologies, 2007. Accessed: 2021-01-28. 